\title{
ENFERMEDAD DE MONDOR REPORTE DE CASO
}

\author{
DANILO E. CIFUENTES BOHÓRQUEZ, MD. ${ }^{1}$, DANIEL SUAREZ JIMÉNEZ, MD. ${ }^{2}$
}

${ }^{1}$ Radiólogo. Universidad militar Nueva Granada. Hospital San Rafael. Docente de Radiología e Imágenes Diagnósticas. Universidad Militar Nueva Granada. Hospital Militar Central. Bogotá. Colombia.

${ }^{2}$ Residente de Radiología e Imágenes Diagnósticas. Universidad Militar Nueva Granada, Hospital Militar Central. Bogotá. Colombia

Recibido: 16 Agosto 2014 Aceptado: 17 Febrero 2015

\begin{abstract}
Resumen
Se presenta un caso de la enfermedad de Mondor, una tromboflebitis de las venas superficiales de la mama. Su diagnóstico se establece clínicamente y se confirma con mamografía y ultrasonido. Es una entidad poco conocida de la cual existe escasa literatura. Se pretende revisar su etiología, fisiopatología y la importancia de la correlación clínico-radiológica de esta entidad ya que para el radiólogo es de vital importancia conocer el diagnóstico diferencial y realizar diagnóstico mediante correlación clínico-imagenológica.
\end{abstract}

Palabras clave: Mondor, Tromboflebitis, venas, mama, ultrasonografía.

\section{MONDOR'S DISEASE: A CASE REPORT}

\begin{abstract}
A case of Mondor's disease is presented, a thrombophlebitis of the superficial veins of the breast. Its diagnosis is established clinically and confirmed by ultrasonography and mammography. This is a rarely known entity with a few data in the literature. A review of the etiology, physiopathology, and the importance of the clinic and radiologic correlation of this entity is pretended, since knowing the differential diagnosis and making the diagnosis through the clinic and imaging correlation is of vital importance for the radiologist.
\end{abstract}

Key words: Mondor, Thrombophlebitis, veins, breast, ultrasonography.

\section{DOENÇA DE MORDO: UM ESTUDO DE CASO}

\begin{abstract}
Resumo
Presenta-se um caso da doença de Mondor, uma tromboflebites das veias superficiais da mama. Seu diagnóstico define-se clinicamente e confirma-se com mamografia e ultra sonido. É uma entidade pouco conhecida da que existe escassa literatura. Pretende-se revisar sua etiologia, fisiopatologia e a importância da correlação clínico-radiológica de esta entidade, pois é muito importante para o radiologista conhecer o diagnóstico diferencial e fazer diagnóstico mediante correlação clínicoprojeção de imagem.
\end{abstract}

Palavras-chave: Mondor, tromboflebites, veias, mama, ultrassonografia. 


\section{Introducción}

La enfermedad de Mondor es una rara entidad descrita por Henry Mondor, caracterizada por ser una tromboflebitis autolimitada de las venas superficiales del tronco, en especial del área mamaria, de carácter benigna.

Su principal causa es de origen traumático, también está asociada a estados de hipercoagulación, cáncer de mama, ejercicio físico, cirugía entre otros.

Se presenta como dolor localizado en trayecto lineal, longitudinal correspondiente a una vena superficial trombosada, generalmente palpable dando la sensación de un cordón subcutáneo doloroso que evoluciona hacia la mejoría en cuestión de semanas.

\section{Caso Clínico}

Paciente de 40 años con cuadro de 20 días de evolución consistente en dolor en hemotórax izquierdo en sentido longitudinal a la altura de la línea axilar anterior, inferior al área mamaria.

Al interrogatorio no presenta antecedentes de importancia.

Los exámenes paraclínicos fueron hallados dentro de los límites normales. Se realiza interconsulta a dermatología quien solicita ultrasonografía Doppler de vasos abdominales la cual no muestra alteraciones y ecografía de tejidos blandos hemitórax izquierdo con el hallazgo de imagen lineal ecogénica en tejido celular subcutáneo correspondiente al área del dolor que por sus características se interpreta como vena superficial trombosada con cambios fibrosos residuales.(Fig 1.)

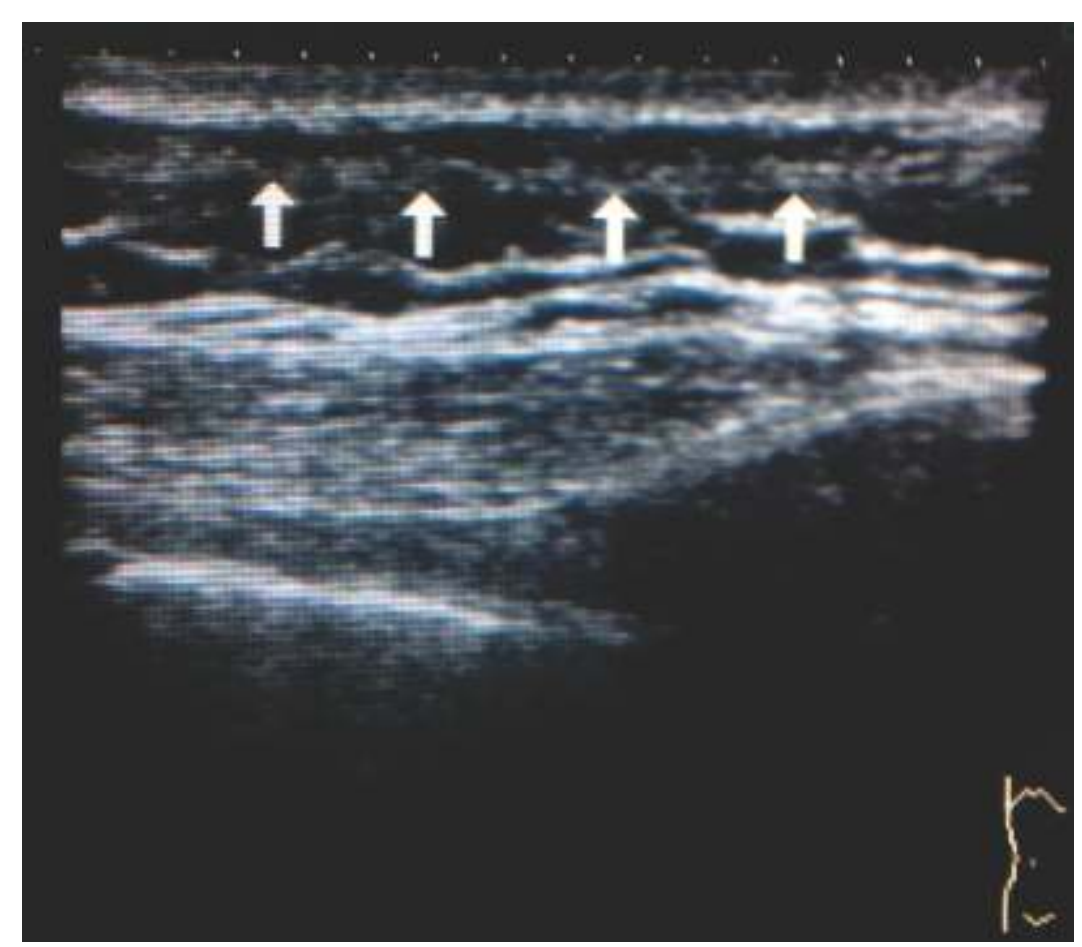

Figura 1. Imagen de ultrasonografía mamaria demostrativa de vena superficial fibrosada por proceso trombótico subagudo realizada en el Hospital Militar Central de Bogotá.

\section{Discusión}

La enfermedad de Mondor fue descrita por primera vez por Faage en 1869 y posteriormente caracterizada por el cirujano francés Henry Mondor en 1939 quien la describió histológicamente como una "angiitis subcutánea" y desde entonces la enfermedad ha llevado su nombre $(1,5)$.
Es una condición benigna autolimitada que consiste principalmente en la oclusión de las venas superficiales del área mamaria y de la pared torácica. Esta entidad se ha descrito en mujeres de mediana edad principalmente aunque se han visto casos reportados en hombres y niños. Anatómicamente las venas más afectadas son la torácica lateral, la toracoepigástrica y epigástrica superior. La 
etiología o patogénesis de esta condición aun no es clara $(1,5)$. Ha sido relacionada comúnmente con trauma directo en la vena o presión en las venas de la pared torácica llevando a estasis de la sangre con posterior formación del trombo. También ha sido asociada a ejercicio físico, cirugía (lumpectomía, reducción mamaria, mamoplastia), biopsia de mama, procesos inflamatorios (artritis, mastitis) y un $12 \%$ está asociada a cáncer de mama (2,5-11).

Si la sintomatología es recurrente, se debe pensar en una coagulopatía sistémica $(4,10)$. Clínicamente se manifiesta como dolor, y algunas veces enrojecimiento de la piel que sigue el trayecto de la vena comprometida. Al examen físico se observa una vena que es dolorosa, generalmente palpable en forma de cordón localizada en la pared torácica y frecuentemente encontrada en el aspecto lateral al área mamaria y asociada en algunas ocasiones con decoloración de la piel $(2-4,10)$.

El diagnóstico se establece clínicamente y se confirma con mamografía y ultrasonido (6-8). En la mamografía la vena trombosada aparece de manera tubular o lineal que raramente se calcifica (2). Sin embargo esta densidad tubular puede confundirse con ductos retroareolares dilatados (1). Una vista tangencial acentúa la superficie natural de la estructura venosa comprometía evitando así la confusión con los ductos dilatados y ayuda a diferenciarla de parénquima mamario denso. El ultrasonido debe ser el primer examen en pacientes jóvenes con una masa palpable.

A través de este estudio se observa una estructura tubular superficial con finos ecos internos no compresible con ausencia de flujo en la ultrasonografía Doppler usualmente localizada en el cuadrante supero-externo $(1,2,4)$. Esto demuestra que el mamografía se complementa con el ultrasonido ya que este último permite identificar el trayecto entero del vaso trombosado el cual no es visible en la mamografía con parénquimas densos y diferenciándola de un ducto el cual es más corto que la vena trombosada y esta última no termina en la areola a diferencia de los ductos galactóforos (1). Teniendo en cuenta estas características imagenológicas el sistema BI-RADS lo ha clasificado en categoría 3 por lo que se recomienda seguimiento en 6 meses si es necesario (1).

El tratamiento incluye analgesia antiinflamatoria, calor local y rehidratación sistémica intravenosa, si la clínica lo amerita. Los antibióticos y los anticoagulantes no están indicados. La complicación más frecuente es la deformidad cosmética debido a la fleboesclerosis y hialinización (3).
La enfermedad de Mondor es una rara entidad que presenta diferentes etiologías que coinciden en estado hipercoagulable. Se requiere hacer un diagnóstico mediante la correlación clínico-radiológica que conlleve a un manejo apropiado.

\section{Conflicto de intereses}

Los autores declaran no tener de manera directa o indirecta ningún tipo de conflicto de intereses financieros, académicos o laborales que puedan poner en peligro la validez de este estudio.

\section{Financiación}

Este trabajo se realizó con recursos propios.

Referencias

1. Shetty M, Watson A. Mondor's Disease of the Breast: Sonographic and Mammographic Findings. AJR. 2001;177:893-896.

2. Sabate J, Clotet M, Gómez A et al. Radiologic Evaluation of Uncommon Inflammatory and Reactive Breast Disorders. RadioGraphics. 2005;25:411-424.

3. Jesinger R, Lattin G, Ballard E. Vascular Abnormalities of the Breast: Arterial and Venous Disorders, Vascular Masses, and Mimic Lesions with Radiologic-Pathologic Correlation. Radiographics. 2011;31:E117-E136.

4. Cao M, Hoyt A et al. Mamographic signs of systemic disease. Radiographics 2011;31:1085-1100

5. Conant E, Wilkes A et al. Superficial thrombophlebitis of the breast (Mondor's Disease): Mammographic findings. AJR Am J Roentgenol. 1993;160:1201-1203.

6. Veronesi P, Zurrida S. Mondor's disease: is there any correlation with breast cancer? The breast. 1995;4(3):170-171.

7. Salemis NS, Merkouris. Mondor's disease of the breast. A retrospective review. Breast Dis 2011;33(3):103-7.

8. Quehe P, Saliou AH et al. Mondor's disease, report on three cases and literature review. J Mal Vasc. 2009;34(1):54-60.

9. Leal B, Vieira $\mathrm{S}$ et al. Mondor's disease in a patient previously treated for carcinoma in situ: a case report. $\mathrm{N} \mathrm{Z} \mathrm{Med} \mathrm{J.}$ 2012;125(1354):100-2.

10. Alvarez-Garrido H. Mondor's disease Clin Exp Dermatol. Clin Exp Dermatol. 2009;34(7):753-6.

11. Duprap E, Miliez PY et al. Mondor's disease and breast plastic surgery. Ann Chir Plast Esthet. 2010;55(3):233-7.

\section{Conclusión}

